Jurnal Sentris KSMPMI Vol. 2 - 2019

\title{
Implementasi Prinsip Fair Trade oleh The Body Shop sebagai Upaya Peningkatan Kesejahteraan Masyarakat Rwanda
}

Oleh: Kathleen Mintarja, Priscilia Christian Kadim, Stella Claresta Alexander

\begin{abstract}
The second half of the twentieth century witnessed unprecedented growth in the number of international actors. There has been a dramatic increase in the number of non-state actors that, on many occasions, helped solve problems and improve lives. This makes the responsibility of people's welfare no longer only held by the government. One of the most prominent examples is the role of Body Shop on improving the living standard of Rwandan. Twenty four years after the genocide that killed almost 800,000 people, the country of Rwanda is rebuilding with the support of international communities, including multinational corporations. The Body Shop's Community Trade commitment has been a key part of bringing local producers into international supply chains and empowering them. Therefore, the research question in this paper is "How is the role of The Body Shop on implementing fair trade principles towards the Rwandan society?" To answer the research question, the authors use several theories and concepts; such as pluralism, multinational companies, and fair trade theory. In addition, the research method to be used by the authors is a qualitative study method. This research found that The Body Shop has launched a Moringa Community Trade program as an embodiment of efforts to improve the welfare of Rwandan people after the genocide occurred. This community trade initiative aims to be one small step forward to achieve financial stability for the people currently living and working in Rwanda.
\end{abstract}

Keywords: Fair Trade, Multinational Corporations, Rwanda, Moringa Community Trade, The Body Shop

\section{Pendahuluan}

Dunia hubungan internasional dalam beberapa dekade terakhir didominasi oleh aktor dan isu yang semakin meluas. Isu yang dibahas dalam hubungan antar negara tidak lagi hanya terkait isu tradisional; yakni keamanan dan perdamaian. Isu non-tradisional kini lebih menjadi 
Jurnal Sentris KSMPMI Vol. 2 - 2019

perhatian setiap negara. Negara menyadari bahwa tanpa adanya keadaan non-militer yang baik, fondasi sebuah negara tidak akan kuat untuk menghadapi tantangan dunia ${ }^{1}$; meliputi isu lingkungan, ekonomi, sosial, budaya, dan masih banyak lagi.

Tidak dapat dipungkiri bahwa salah satu isu terpenting di antaranya adalah ekonomi. Isu ekonomi seringkali dianggap sebagai isu "high politics" menggantikan militer dan politik. Kekhawatiran akan implikasi domestik dari stagflasi dari negara-negara industri maju telah mendorong permintaan untuk meningkatkan kegiatan ekonomi. Seiring berjalannya waktu, pertumbuhan ekonomi menjadi salah satu fokus utama bagi suatu negara; dengan pembangunan ekonomi menjadi tujuan utama. ${ }^{2}$ Dewasa ini, kekuatan suatu negara tidak hanya dilihat dari kekuatan militer belaka melainkan tingkat pertumbuhan ekonominya. Negaranegara dengan great power cenderung memiliki perekonomian yang stabil dan terus berkembang di negaranya. Semua hal ini menunjukkan bahwa faktor ekonomi menjadi hal yang begitu penting demi perkembangan suatu negara; baik secara fisik maupun sosial. Secara fisik, negara harus memiliki infrastruktur dan fasilitas yang memadai. Secara sosial, masyarakat yang berada di dalam suatu negara harus memiliki tingkat produktivitas yang tinggi.

Seiring dengan isu yang semakin meluas, aktor dari hubungan internasional juga semakin beragam. Tidak hanya aktor negara, aktor non-negara juga terlibat dalam berbagai aktivitas internasional. Dengan demikian, dalam mengurus aktivitas hubungan internasional pemerintah resmi tidak lagi harus terlibat secara langsung. Beberapa pihak berpendapat bahwa globalisasi ekonomi memberikan lokus tidak hanya kepada pemerintah negara, melainkan juga aktor lainnya; seperti perusahaan multinasional, pemerintah daerah, organisasi supranasional, dan kelompok kepentingan tertentu. ${ }^{3}$

Fakta tersebut menunjukkan situasi dan kondisi internal dari setiap negara bahwa tanggung jawab atas kesejahteraan masyarakat tidak hanya dikontrol oleh pemerintah. Aktor non-negara; seperti perusahaan multinasional, kelompok kepentingan, serta individu; menjadi

\footnotetext{
${ }^{1}$ Torbjorn L. Knutsen, "THE DEVELOPMENT OF INTERNATIONAL RELATIONS", Department of Politics and International Relations, University of Trondheim (NTNU), International Relations Vol. 1 (2014), diakses 3 Maret 2019, www.eolss.net/sample-chapters/c14/e1-35-01.pdf

${ }^{2}$ R.J. Barry Jones, "International Political Economy: Problems and Issues: Part I", Review of International Studies Vol. 7, No. 4 (1981): 245-260, diakses 3 Maret 2019, https://www.jstor.org/stable/20096927
}

${ }^{3}$ Miles Kahler dan David A. Lake, Governance in a Global Economy Political Authority in Transition (Princeton: Princeton University Press, 2003): 0-51 
Jurnal Sentris KSMPMI Vol. 2 - 2019

salah satu pengaruh penting dalam penggerak perekonomian negara. Aktor non-negara secara signifikan mempengaruhi perilaku kebijakan luar negeri dan domestik. Mereka berperan besar dalam negosiasi di lingkungan domestik dan internasional; baik sebagai home state ataupun host state. ${ }^{4}$

Dalam penelitian ini, penulis menekankan pada peran dari perusahaan multinasional; yakni The Body Shop. The Body Shop merupakan sebuah perusahaan produk kosmetik yang terkenal oleh produk-produknya yang menggunakan komposisi herbal. The Body Shop merupakan perusahaan franchise kosmetik terbesar kedua di dunia. Pada tahun 1987, The Body Shop meluncurkan program Trade Not Aid yang bertujuan untuk mengentas kemiskinan dan penderitaan yang terjadi di negara-negara berkembang. ${ }^{5}$ Seiring dengan berjalannya waktu, program Trade Not Aid berkembang menjadi Community Trade. Program ini memenuhi lima nilai utama yang dijadikan sebagai komitmen dalam berbisnis; salah satunya adalah poin "Support Community Fair Trade”. Poin tersebut menekankan pentingnya pemberdayaan komunitas berskala kecil dengan produk-produk orisinal. ${ }^{6}$

Dengan adanya program Community Trade, kelompok usaha berskala kecil mendapatkan kesempatan untuk meningkatkan derajat hidup mereka. Sejak diberlakukannya program Community Trade, The Body Shop telah memasok produk perusahaanya menggunakan bahan-bahan dari komunitas yang termarjinalisasi seperti produsen kecil, pekerja perempuan, dan kaum difabel. Selain itu, program ini juga telah memberikan pekerjaan bagi hampir 300.000 orang di seluruh dunia. ${ }^{7}$ Salah satu target dari program Community Trade milik The Body Shop tersebut adalah Rwanda.

Pada tanggal 6 April 1994, terjadi pembunuhan brutal antara masyarakat Hutu dan Tutsi yang menewaskan sekitar 800.000 orang di Rwanda. ${ }^{8}$ Tindakan pembunuhan massal ini telah menjadi salah satu peristiwa genosida terburuk yang pernah terjadi di dalam sejarah dunia.

\footnotetext{
${ }^{4}$ Muhittin Ataman, "The Impact of Non-State Actors on World Politics: A Challenge to Nation-States", Alternatives: Turkish Journal of International Relations Volume 2 Number 1 (2003), https://dergipark.org.tr/download/article-file/19401 (Diakses 12 Mei, 2019)

${ }^{5}$ Anita Roddick, Body and Soul: Profits with Principles, (New York: Three Rivers, 1991).

${ }^{6}$ Putu Wahyu Mila Sari, Sukma Sushanti, I Made Anom Wiranata, “Upaya The Body Shop dalam Mendukung Penerapan Prinsip Fair Trade di Bidang Lingkungan dalam Aktivitas Bisnisnya," https://ojs.unud.ac.id/index.php/hi/article/view/12141, (Diakses 12 Mei, 2019).

${ }^{7}$ Ibid.

${ }^{8}$ Des Forges, A. Leave none to tell the history: Genocide in Rwanda. New York, London, Brussels: Human Rights Watch, 1999.
} 
Jurnal Sentris KSMPMI Vol. 2 - 2019

Semua tragedi ini terjadi dikarenakan adanya ketegangan antara etnis Hutu dan Tutsi yang sudah terjadi selama bertahun-tahun. Tindakan pembunuhan massal dilakukan oleh masyarakat Hutu yang mendukung gerakan anti-Tutsi. Setiap masyarakat Tutsi akan dibunuh secara langsung; baik dengan pisau ataupun senjata tangan lainnya. Sebelum dibunuh, seringkali masyarakat Tutsi disiksa terlebih dahulu, dan ribuan perempuan Tutsi diperkosa dan dijadikan sebagai budak seks. ${ }^{9}$ Salah satu kasus terburuk dari genosida Rwanda ini adalah pembunuhan massal yang dilakukan di salah satu gereja Katolik di dekat ibu kota. Pada saat itu, walikota yang merupakan seorang etnis Hutu meminta masyarakat Tutsi untuk berlindung di gereja. Akan tetapi, walikota tersebut berkhianat dan menyerahkan suku Tutsi kepada para ekstrimis Hutu untuk dibunuh. ${ }^{10}$ Tindakan genosida ini merupakan tindakan yang sangat kejam dan kemudian diakhiri dengan kemenangan dari Rwandan Patriotic Front pada bulan Juli 1994. ${ }^{11}$ Pada saat genosida berakhir, Rwanda sudah berada di ambang kehancuran ekonomi. Hampir setiap infrastruktur seperti sekolah, rumah sakit, gereja, dan lainnya runtuh. Selain itu, konflik juga memaksa lebih dari dua juta orang Rwanda meninggalkan negara tersebut, sedangkan satu juta orang kehilangan tempat tinggal. ${ }^{12}$

Dalam menganalisis upaya The Body Shop dalam memperbaiki situasi finansial di Rwanda, penulis akan menggunakan prinsip Fair Trade agar diketahui maksud dan tujuan dari setiap tindakan yang dilakukan berdasarkan komponen-komponen prinsip tersebut. Dengan demikian, penelitian ini mengambil pertanyaan penelitian berupa, "Bagaimana implementasi prinsip Fair Trade oleh The Body Shop dalam meningkatkan kesejahteraan masyarakat Rwanda?" Adapun penulis mengangkat penelitian ini karena termotivasi dari komitmen perusahaan The Body Shop itu sendiri; yakni "Enrich our planet, Enrich our product, Enrich our people". ${ }^{13} \mathrm{Hal}$ ini menunjukkan bahwa seiring dengan upaya mengembangkan bisnisnya, The Body Shop akan terus berteguh pada tanggung jawabnya untuk memperhatikan kondisi sekitarnya; yakni lingkungan dan masyarakat.

\footnotetext{
${ }^{9}$ Donatien Nizuke, "The Genocide against the Tutsi in Rwanda: Origins, causes, implementation, consequences, and the post-genocide era," International Journal of Development and Sustainability Vol 3 No 5 (2014): 10861098.

10 ibid

${ }^{11}$ Ibid

${ }^{12}$ Ibid.

${ }^{13}$ The Body Shop, “Commitment,” https://www.thebodyshop.co.id/commitment/, (Diakses 12 Mei, 2019)
} 
Jurnal Sentris KSMPMI Vol. 2 - 2019

\section{Kerangka Teori}

Pada bagian kerangka pemikiran, penulis akan menjabarkan beberapa konsep dan teori dari Hubungan Internasional yang relevan dengan fenomena penelitian yang akan diteliti untuk menjawab pertanyaan penelitian mengenai implementasi prinsip-prinsip fair trade oleh The Body Shop di Rwanda. Sebagai bagian dari ilmu sosial, ilmu Hubungan Internasional dapat dikatakan merupakan disiplin ilmu yang sangat dinamis. Seiring dengan perkembangan definisi HI, perluasan aktor dalam studi Hubungan Internasional juga terjadi. Fenomena tersebut dapat dijelaskan melalui teori pluralisme. Menurut Viotti dan Kauppi, ada empat asumsi dasar dalam melihat hubungan internasional melalui pemikiran pluralisme. Pertama, aktor non-negara merupakan aktor yang penting dalam studi Hubungan Internasional. Kedua, negara bukan aktor tunggal atau unitary actor. Negara merupakan hasil kompetisi dan kerja sama antar individu, kelompok kepentingan dan birokrasi sehingga keputusan yang dikeluarkan bukan murni dari suatu bentuk yang menamakan dirinya negara, melainkan dari hasil proses kompetisi dan kerjasama tadi. Maka dari itu, ada entitas lain yang juga berperan dalam hubungan internasional seperti individu, kelompok kepentingan dan lembaga birokrasi. $^{14}$

Ketiga, negara bukan aktor yang rasional. Negara mempunyai kepentingan dan kebutuhan tersendiri dalam mengambil sebuah keputusan. Keputusan tersebut tentu melewati proses kompromi terlebih dahulu sehingga keputusan belum tentu bersifat rasional. Terakhir, masalah yang dibahas dalam politik internasional bersifat berkembang dan meluas. ${ }^{15}$ Oleh sebab itu, masalah keamanan nasional bukan menjadi satu-satunya masalah utama saat ini. Namun, isu lain seperti ekonomi, sosial dan lingkungan hidup juga menjadi isu utama dalam politik internasional. ${ }^{16}$ Atas dasar keempat asumsi dasar pluralisme tersebut maka Perusahaan Multinasional (PMN) adalah salah satu aktor non-negara yang turut serta berperan dalam dunia internasional.

Menurut Colman dan Nixxon, PMN adalah satu unit usaha yang memiliki atau mengontrol aset-aset seperti pabrik, pertambangan, perkebunan, outlet (pusat penjualan) dan

\footnotetext{
${ }^{14}$ Paul R. Viotti dan Mark Kauppi, International Relations Theory: Realism, Pluralism, Globalism, (New York: Macmillan Publishing, 1990), 192-193.

${ }^{15}$ Ibid.

${ }^{16}$ Paul R. Viotti dan Mark Kauppi, International Relation Theory: Realism, Pluralism, Globalism, (New York: Macmillan Publishing, 1990): 192-193.
} 
Jurnal Sentris KSMPMI Vol. 2 - 2019

perkantoran yang terdapat di dua atau lebih negara. ${ }^{17} \mathrm{PMN}$ juga memiliki empat karakteristik menurut Michael J. Carbaugh, yaitu pertama, PMN merupakan perusahaan bisnis yang beroperasi di dua atau lebih negara tujuan (host country) dengan negara induk PMN berada di negara asalnya (home country); kedua, seringkali PMN melakukan aktivitas research and development di negara tujuan; ketiga, kegiatan operasional perusahaan adalah lintas batas negara; terakhir, pemindahan modal asing yang ditandai dengan arus foreign direct investment dari wilayah yang sedikit memberikan keuntungan kepada PMN dianggap mampu memberikan kontribusi positif atas keberadaan PMN. ${ }^{18}$

Seiring dengan perkembangan ekonomi global, PMN pun gencar melakukan ekspansi khususnya ke negara-negara berkembang sejak tahun 1970-an. Namun, kehadiran PMN di negara tujuan tidak selalu mendapat tanggapan positif, dan tidak sedikit pula yang berpandangan negatif. Untuk menyeimbangkan antara kegiatan mencari keuntungan dan menanggapi kekhawatiran masyarakat atas kehadirannya, PMN pun dituntut untuk melakukan tanggung jawab sosial seperti melalui implementasi prinsip-prinsip fair trade. Dalam menjawab pertanyaan penelitian yang telah diuraikan sebelumnya, penulis akan menggunakan kerangka teori berupa sepuluh prinsip fair trade yang telah disusun oleh World Fair Trade Organization. Berikut adalah penjelasan dari sepuluh prinsip tersebut: ${ }^{19}$

\section{Opportunities for Disadvantaged Producers}

Prinsip pertama adalah adanya pemberian kesempatan bagi para produsen yang miskin atau seringkali rugi untuk meningkatkan kesejahteraannya. Strategi fair trade dalam prinsip ini mendukung produsen kecil yang terpinggirkan untuk keluar dari kemiskinan. Demi mencapai efisiensi serta kemandirian ekonomi dalam waktu jangka panjang, organisasi fair trade memiliki beberapa rencana untuk mencapai prinsip tersebut; seperti mengadakan kemitraan perdagangan dengan para produsen yang terpinggirkan, mengadakan pelatihan kepemimpinan, memberi pendidikan, dan sebagainya.

\footnotetext{
${ }^{17}$ Bob Sugeng Hadiwinata, Investasi Asing dan Perusahaan Multinasional, (Jakarta: Kanisius, 2002), 117.

${ }^{18}$ Aknolt Kristian Pakpahan dalam Yulius P. Hermawan, Transformasi dalam Studi Ilmu Hubungan Internasional, Multinational Corporation dan Implementasi Corporate Social Responsibility dalam Perekonomian Global, (Yogyakarta: Graha Ilmu, 2007), 211.

${ }^{19}$ World Fair Trade Organization, “10 Principles of Fair Trade, ” https://wfto.com/fair-trade/10-principles-fairtrade (Diakses 12 Mei, 2019)
} 
Jurnal Sentris KSMPMI Vol. 2 - 2019

\section{Transparency and Accountability}

Prinsip kedua adalah mengembangkan hubungan yang transparan dan dapat dipertanggungjawabkan. Prinsip ini menekankan adanya proses keterbukaan yaitu memberi kesempatan bagi seluruh pihak dalam menyampaikan pendapat selama proses pengambilan keputusan. Oleh sebab itu, fair trade menginginkan adanya hubungan yang terbuka, adil, konsisten, dan penuh hormat. Para produsen dan konsumen serta anggota fair trade harus saling berbagi informasi selama proses perdagangan.

\section{Fair Trade Practices}

Prinsip fair trade yang ketiga adalah praktik perdagangan yang adil. Organisasi fair trade berfokus pada kesejahteraan sosial dan ekonomi para produsen kecil dan tidak mencari keuntungan. Dalam pelaksanaan fair trade, penting sekali bagi para produsen, pemasok dan konsumen untuk memiliki perilaku yang bertanggung jawab dan profesional. Prinsip ini menginginkan adanya hubungan jangka panjang yang berdasarkan pada rasa kepercayaan serta rasa hormat terhadap sesama. Selain itu, prinsip ini mengutamakan komunikasi antar seluruh pihak yang terlibat.

\section{Fair Payment}

Prinsip yang keempat adalah pembayaran yang adil. Dalam perdagangan menggunakan prinsip fair trade, harga suatu produk harus berdasarkan pada persetujuan dari seluruh pihak. Produsen akan mendapatkan harga yang sesuai karena dalam proses penentuan harga, fair trade memiliki aturan harga minimum yang sudah ditentukan berdasarkan biaya waktu, tenaga kerja, bahan baku, dan lain sebagainya. Selain itu, prinsip ini juga mengutamakan adanya pembayaran yang sama baik terhadap para pekerja laki-laki ataupun perempuan. Pendapatan harus didistribusikan secara adil.

\section{No Child Labour, No Forced Labour}

Prinsip kelima menekankan pada tidak adanya pekerja anak dan kerja paksa. Namun, apabila suatu negara atau daerah (biasanya terjadi pada negara miskin) memperbolehkan adanya pekerja anak, maka produsen fair trade dapat menggunakan jasa pekerja anak. Akan tetapi, perlu diperhatikan juga bahwa seluruh proses produksi yang melibatkan anak-anak harus terbuka dan diawasi. Selain itu, seluruh tenaga kerja yang terlibat harus berdasarkan atas persetujuannya sendiri tanpa ada rasa dipaksa oleh pihak lain. 
Jurnal Sentris KSMPMI Vol. 2 - 2019

\section{No Discrimination, Gender Equity, Freedom of Association}

Prinsip keenam adalah tidak ada diskriminasi, kesetaraan gender dan kebebasan berserikat. Fair trade menekankan tidak boleh adanya diskriminasi berdasarkan agama, ras, umur dan sebagainya, dalam proses rekrutmen, pemberian gaji, pelatihan, pemberhentian atau pensiun. Kelompok fair trade juga memiliki kebijakan untuk memastikan bahwa laki-laki dan perempuan memiliki kesempatan yang sama dalam mengakses sumber daya serta menyatakan pendapat dalam proses pengambilan keputusan. Di sisi lain, fair trade menghormati hak seluruh karyawan untuk bergabung dalam serikat kerja dan berunding bersama-sama demi menjamin adanya kemandirian dan kebebasan.

\section{Good Working Conditions}

Prinsip ketujuh adalah adanya lingkungan kerja yang aman dan sehat dengan memenuhi standar hukum lokal, nasional dan perjanjian dengan International Labor Organisations. Hal ini dalam artian jam kerja, kondisi kesehatan, praktik kerja yang aman menjadi perhatian utama bagi para kelompok fair trade. Oleh sebab itu, dapat disimpulkan bahwa fair trade menekankan pada adanya lingkungan kerja yang kondusif bagi para karyawannya.

\section{Capacity Building}

Prinsip kedelapan adalah pembangunan kapasitas. Hal ini dapat dilakukan dengan cara mengembangkan keahlian dan kemampuan para produsen. Fair trade juga bertujuan untuk membantu produsen dalam hal komunikasi, bantuan keuangan, informasi pasar, dan sebagainya. Dengan meningkatkan kapasitas para produsen kecil dan terpinggirkan, maka para produsen tersebut dapat memiliki akses terhadap pasar serta mengembangkan bisnisnya.

\section{Promote Fair Trade}

Prinsip kesembilan adalah mempromosikan fair trade. Kelompok fair trade bertujuan meningkatkan kesadaran masyarakat mengenai fair trade serta mencapai keadilan dalam dunia perdagangan. Hal ini dapat dilakukan dengan memberikan informasi mengenai fair trade kepada pembeli, produsen, dan sebagainya. Dalam mempromosikan fair trade, prinsip ini menekankan pada teknik pemasaran yang bersifat jujur atau apa adanya.

\section{Respect for the Environment}

Prinsip yang terakhir adalah menghargai lingkungan. Kelompok fair trade diwajibkan untuk memaksimalkan penggunaan bahan baku yang berkelanjutan. Tidak hanya itu, mereka 
Jurnal Sentris KSMPMI Vol. 2 - 2019

juga harus menggunakan teknologi ramah lingkungan yang meminimalisasi emisi gas efek rumah kaca. Kemudian, kelompok fair trade juga harus memastikan tidak adanya limbah yang berlebihan di lingkungan sekitarnya. Jika memungkinkan, kemasan produk juga menggunakan bahan yang dapat didaur ulang dengan mudah. ${ }^{20}$

\section{Analisis}

Salah satu contoh program Community Trade yang dapat dikatakan sukses adalah program Moringa Community Trade. Pada tahun 2012, The Body Shop bekerjasama dengan perusahaan Asili Natural Oils di Rwanda. Perusahaan ini merupakan wadah bagi petani tumbuhan Moringa lokal yang kemudian diolah menjadi minyak biji Moringa. Program Moringa Community Trade milik The Body Shop melibatkan petani-petani lokal yang bertanggung jawab penuh dalam keseluruhan proses pengolahan minyak biji moringa. ${ }^{21}$ Pada tahun 2010, Moringa menjadi salah satu produk The Body Shop dengan penjualan tertinggi secara global.

Sejalan dengan prinsip Fair Trade poin pertama yaitu Opportunities for Disadvantaged Producers, program Moringa Community Trade berhasil memberikan kesempatan bagi petani lokal di Rwanda untuk menghasilkan pendapatan berkelanjutan. Pasca kasus genosida yang terjadi pada tahun 1994, Rwanda telah bekerja keras untuk membangun kembali negara mereka demi tercapainya stabilitas finansial. Salah satu komoditas potensial yang dimanfaatkan oleh penduduk Rwanda adalah tumbuhan Moringa yang terkenal kaya akan kandungan antioksidan dan omega sembilan. Namun, pemanfaatan tumbuhan Moringa menemukan kendala yaitu kurangnya pembeli akibat akses terhadap pasar internasional yang masih terbatas. Hal ini menimbulkan kekecewaan bagi para petani Moringa, sehingga banyak yang memutuskan untuk tidak lagi menjadikan tumbuhan Moringa sebagai sumber pendapatan. ${ }^{22}$ Sejak diberlakukan pada tahun 2012, program Moringa Community Trade berhasil membuka akses bagi 2.137 petani tumbuhan moringa di Rwanda terhadap pasar internasional, sehingga

\footnotetext{
${ }^{20}$ World Fair Trade Organization, “10 Principles of Fair Trade,” https://wfto.com/fair-trade/10-principles-fairtrade (Diakses 12 Mei, 2019)

${ }^{21}$ The Body Shop, "Community Trade Moringa Seed Oil From Rwanda," https://www.thebodyshop.com/enhk/ingredient/moringa-new (Diakses 12 Mei, 2019)

22 Medium, "Making Moringa Work (And Other Miracles), 1 Juni 2018, https://medium.com/@TheBodyShop/making-moringa-work-and-other-miracles-f1cae49f8a0a, (Diakses 12 Mei, 2019)
} 
Jurnal Sentris KSMPMI Vol. 2 - 2019

berkontribusi besar terhadap pendapatan petani lokal. Berkat program Moringa Community Trade milik The Body Shop, petani Moringa di Rwanda mendapatkan akses untuk menjual minyak Moringa di dalam pasar internasional, sebuah kesempatan yang dulu dapat dikatakan mustahil untuk tercapai.

Selain itu, program Moringa Community Trade juga berupaya untuk memenuhi prinsip Fair Trade poin kedua, yaitu Transparency and Accountability, yaitu terwujudnya hubungan yang transparan dan dapat dipertanggungjawabkan antara seluruh pihak yang terlibat dalam program dimulai dari produsen hingga konsumen. Perwakilan The Body Shop bekerja keras untuk membangun kepercayaan, transparansi, dan menjalin pertemanan dengan petani lokal untuk memastikan terjaminnya masa depan mereka dan keluarga mereka. Hal ini dilakukan dengan cara melibatkan para petani lokal dalam setiap pengambilan keputusan dalam keseluruhan proses produksi produk Moringa. ${ }^{23}$

Upaya The Body Shop dalam menjalin relasi yang baik dengan seluruh pemangku kepentingan merupakan salah satu bentuk pemenuhan prinsip Fair Trade poin ketiga, yaitu Fair Trade Practices. Poin ini menekankan pentingnya perilaku yang bertanggung jawab dan profesional demi terwujudnya hubungan jangka panjang. Oleh sebab itu, The Body Shop memiliki persyaratan dan kualifikasi yang harus dipenuhi oleh petani lokal Rwanda apabila hendak bergabung dengan program Moringa Community Trade. Setelah bergabung, petani lokal tetap harus mematuhi aturan yang telah ditetapkan oleh The Body Shop melalui perjanjian tertulis. ${ }^{24}$ Tidak hanya itu, The Body Shop juga menetapkan standar-standar bagi seluruh pemangku kepentingan, seperti petani lokal dan perusahaan Asili Natural Oils, demi terjaganya hubungan yang baik antar seluruh pihak yang terlibat.

Setelah praktek perdagangan yang adil, prinsip Fair Trade juga menekankan pentingnya pembayaran yang adil (Fair Payment), Dalam perdagangan Fair Trade, harga suatu produk harus ditentukan berdasarkan hasil kesepakatan setiap pihak yang terlibat. Salah satu target dari program Moringa Community Trade adalah membantu penduduk Rwanda mencapai keamanan finansial. Karena peraturan dalam pasar internasional umumnya bersifat diskriminatif terhadap produsen kecil, peran The Body Shop selaku perusahaan besar dibutuhkan untuk mengangkat

\footnotetext{
${ }^{23}$ The Body Shop, "Moringa dari India," https://www.thebodyshop.co.id/all-ingredients/moringa.html, (Diakses 12 Mei, 2019)

${ }^{24}$ Refinery, "These Brands Go One Step Beyond Donations to Empower Women Globally, “ https://www.refinery29.com/en-us/2018/03/192955/beauty-products-benefiting-women, (Diakses 12 Mei, 2019)
} 
Jurnal Sentris KSMPMI Vol. 2 - 2019

derajat para petani Moringa di Rwanda, sehingga mereka tidak lagi hidup di bawah garis kemiskinan. The Body Shop juga berkomitmen untuk membeli minyak Moringa dengan harga yang telah ditentukan berdasarkan biaya waktu, tenaga kerja, bahan baku, dan sebagainya. ${ }^{25}$ Hal ini dilakukan untuk mendukung integrasi Moringa Community Trade dalam produk perusahaan mereka. Penawaran yang diberikan oleh The Body Shop kepada petani lokal dapat membuka akses bagi pembeli berskala besar lainnya. Pada akhirnya, lebih dari 2.000 petani lokal Rwanda yang bekerja sama dengan The Body Shop dan Asili Natual Oils akan memiliki pendapatan yang cukup untuk mengangkat derajat dan martabat kehidupan mereka. ${ }^{26}$

Program Moringa Community Trade juga menekankan prinsip No Child and Forced Labour. Poin kelima dalam prinsip Fair Trade tersebut melarang keterlibatan pekerja anak atau pekerja paksa. Dalam program ini, petani lokal yang terlibat umumnya berasal dari kelompok angkatan kerja. The Body Shop juga memiliki code of conduct atau kode etik yang dapat membantu para petani atau supplier untuk mengikuti segala kualifikasi dan aturan yang telah ditetapkan oleh perusahaan dengan benar. Salah satu isi code of conduct The Body Shop adalah tidak diizinkan untuk menggunakan tenaga anak dibawah umur. ${ }^{27}$ Petani lokal yang dipekerjakan dalam program ini telah memiliki kualifikasi yang sesuai dengan aturan tersebut, mengingat sebelum terlibat dalam program Moringa Community Trade, para petani diwajibkan untuk menandatangani kontrak tertulis. Selain itu, testimoni yang diberikan oleh petani-petani lokal cenderung positif. Berkat program Moringa Community Trade, cinta dan kepercayaan mereka terhadap tumbuhan Moringa kembali muncul. Hingga saat ini, belum pernah ditemukan kasus pekerja paksa dalam Moringa Community Trade karena para petani lokal memiliki rasa kepemilikan yang tinggi terhadap tumbuhan Moringa. ${ }^{28}$

Selain itu, The Body Shop juga mengimplementasikan prinsip keenam fair trade yaitu tidak ada diskriminasi, kesetaraan gender dan kebebasan berserikat. Dalam Moringa

\footnotetext{
${ }^{25}$ Medium, "Making Moringa Work (And Other Miracles)," 1 Juni, 2018, https://medium.com/@TheBodyShop/making-moringa-work-and-other-miracles-f1cae49f8a0a (Diakses 12 Mei, 2019).

${ }^{26}$ Rachel Adler, "24 Years After the Rwandan Genocide, The Country's Moringa Oil is Helping Rebuild," https://fashionista.com/2018/02/the-body-shop-rwanda-moringa-oil (Diakses 12 Mei, 2019).

${ }^{27}$ The Body Shop, “The Body Shop Code of Conduct for Supplier,” 2013, http://www.thebodyshop.ca/fr/pdfs/valuescampaigns/THEBODYSHOPCODEOFCONDUCTforsuppliers.pf. (Diakses 10 Mei 2019).

${ }^{28}$ Siobhan Norton, "How the Body Shop is using moringa oil to help rural Rwandans lift themselves out of poverty," https://inews.co.uk/news/long-reads/how-the-body-shop-is-using-moringa-oil-to-help-rural-rwandanslift-themselves-out-of-poverty/ (Diakses $12 \mathrm{Mei}, 2019)$.
} 
Jurnal Sentris KSMPMI Vol. 2 - 2019

Community Trade, para petani atau koperasi kecil harus menandatangani dukungan pada "Ethical Trade Program" yang dibuat untuk meningkatkan kondisi dan hak-hak pekerja selama proses pembuatan bahan baku produk The Body Shop. Kesepakatan ini memungkinkan The Body Shop untuk memastikan bahwa tidak ada diskriminasi, ketidakadilan, dan situasi kerja yang tidak representatif. ${ }^{29}$ Oleh sebab itu, Moringa Community Trade harus memberi kesempatan yang sama bagi laki-laki dan perempuan Rwanda untuk mengakses sumber daya serta menyatakan pendapat dalam proses pengambilan keputusan. Selain itu, salah satu poin dari code of conduct The Body Shop adalah karyawan berhak untuk membentuk asosiasi pekerja dan memiliki hak menawar pada perusahaan. ${ }^{30}$ Ini menunjukkan bahwa pembentukkan Moringa Community Trade telah sesuai dengan prinsip keenam fair trade yaitu kebebasan berasosiasi.

Prinsip ketujuh yang juga menjadi bagian dari implementasi fair trade oleh The Body Shop adalah adanya lingkungan kerja yang aman dan sehat dengan memenuhi standar hukum lokal, nasional dan perjanjian dengan International Labor Organization (ILO). Untuk mendukung hal tersebut, The Body Shop juga telah menekankan prinsip ini dalam salah satu poin code of conduct-nya yaitu para petani atau supplier tidak diperkenankan untuk memberi shift malam kepada para karyawan atau bekerja di tempat berbahaya, dan tidak diizinkan untuk melebihi jam kerja yang standar atau sesuai dengan aturan dari ILO ${ }^{31}$ Dengan begitu, Moringa Community Trade diwajibkan untuk menyediakan lingkungan kerja yang aman dan sehat bagi para karyawannya karena hal tersebut merupakan salah satu perhatian utama bagi The Body Shop.

Selain itu, prinsip kedelapan fair trade adalah pembangunan kapasitas. Hal ini berarti mengembangkan keahlian dan kemampuan para petani Moringa di Rwanda. Dalam Moringa Community Trade, The Body Shop telah mengadakan beberapa program dan pelatihan untuk membantu sekitar 832 petani yang ada seperti memberi pelatihan mengenai bisnis, membantu bagaimana mereka dapat melindungi tanah mereka, bagaimana mereka dapat menyirami

\footnotetext{
29 Ibid.

${ }^{30}$ Putu Wahyu Mila Sari, Sukma Sushanti, dan I Made Anom Wiranata, "Upaya the Body Shop dalam Mendukung Prinsip Fair Trade di Bidang Lingkungan dalam Aktivitas Bisnisnya," Universitas Udayana (2016): 7.

31 The Body Shop, "The Body Shop Code of Conduct for Supplier," 2013, http://www.thebodyshop.ca/fr/pdfs/valuescampaigns/THEBODYSHOPCODEOFCONDUCTforsuppliers.pf. (Diakses 10 Mei 2019).
} 
Jurnal Sentris KSMPMI Vol. 2 - 2019

tanaman dengan efisien. ${ }^{32}$ Tidak hanya itu, perusahaan the Body Shop juga mengunjungi keluarga para petani untuk memahami kondisi kehidupan dan perkebunan dari para petani, serta tantangan-tantangan yang dihadapi pada saat memproduksi tanaman Moringa; ataupun masalah sosial yang lebih luas, seperti akses terhadap air. ${ }^{33}$ Dalam hal ini, The Body Shop melalui Moringa Community Trade mencoba untuk meningkatkan kapasitas para petani agar para produsen tersebut dapat memiliki akses terhadap pasar serta mengembangkan bisnisnya.

Prinsip kesembilan yang juga diimplementasikan oleh The Body Shop dalam Moringa Community Trade adalah mempromosikan fair trade. Dalam hal ini, The Body Shop memiliki tujuan untuk meningkatkan kesadaran masyarakat dunia mengenai fair trade serta mencapai keadilan dalam dunia perdagangan. Hal ini telah dilakukan dengan adanya inisiatif program Community Trade yang telah dilakukan oleh The Body Shop sejak tahun 1987. The Body Shop merupakan salah satu dari beberapa perusahaan multinasional besar yang menerapkan fair trade dari proses produksi hingga penjualan di setiap gerai waralabanya di seluruh dunia. Dengan adanya Community Fair Trade ini, The Body Shop dapat memberikan pekerjaan bagi hampir 300.000 orang di seluruh dunia, serta petani ataupun kelompok usaha berskala kecil menengah juga memungkinkan untuk mendapat kehidupan layak yang berkesinambungan. ${ }^{34}$ Community Fair Trade The Body Shop terdiri dari berbagai kelompok petani berskala kecil dari berbagai belahan dunia, dan salah satunya adalah Rwanda dalam bentuk Moringa Community Trade. Program ini menjadi salah satu cara bagi The Body Shop untuk mempromosikan praktik fair trade ke seluruh dunia.

Terakhir, prinsip fair trade yang diimplementasikan oleh The Body Shop adalah menghargai lingkungan. Dalam kasus ini, The Body Shop berkomitmen untuk mengurangi dampak terhadap lingkungan dari aktivitas bisnis. Setiap community trade seperti Moringa harus ikut serta dalam upaya mengurangi dampak lingkungan melalui inovasi dalam pembangkit energi hijau, penghematan energi, pembelian energi hijau, menggunakan sistem manajemen yang efektif. Komitmen The Body Shop melalui community trade dalam upayanya

\footnotetext{
${ }^{32}$ Melissa Mason, "This is The Behind-The-Scenes Work That Goes Into A Community Trade Partnership," Pedestrian, https://www.pedestrian.tv/news/community-trade-body-shop-australia/ (diakses 12 Mei 2019).

${ }^{33}$ Putu Wahyu Mila Sari, Sukma Sushanti, dan I Made Anom Wiranata, "Upaya the Body Shop dalam Mendukung Prinsip Fair Trade di Bidang Lingkungan dalam Aktivitas Bisnisnya,” Universitas Udayana (2016): 7.

34 The Body Shop, “Community Trade Moringa Seed Oil from Rwanda,” https://www.thebodyshop.com/enhk/ingredient/moringa-new (Diakses 10 Mei 2019).
} 
Jurnal Sentris KSMPMI Vol. 2 - 2019

penghematan sumber energi dan penggunaan energi ramah lingkungan dapat dilihat pada tabel di bawah ini ${ }^{35}$ :

\begin{tabular}{|c|c|c|c|}
\hline \multirow{2}{*}{ Target } & \multirow{2}{*}{ Lokasi } & \multicolumn{2}{|c|}{ Waktu } \\
\hline & & Target & Awal \\
\hline $\begin{array}{l}\text { Mengurangi emisi } \\
\text { gas } \mathrm{CO}_{2} \\
\text { sebanyak } 50 \%\end{array}$ & $\begin{array}{l}\text { Toko-Toko The } \\
\text { Body Shop }\end{array}$ & 2020 & 2010 \\
\hline $\begin{array}{l}\text { Mengurangi emisi } \\
\text { gas } \mathrm{CO}_{2} \\
\text { sebanyak } 50 \%\end{array}$ & $\begin{array}{c}\text { Kantor dan } \\
\text { Kantor Distribusi } \\
\text { Regional }\end{array}$ & 2015 & 2005 \\
\hline $\begin{array}{l}\text { Mengurangi } \\
\text { sampah sebesar } \\
50 \%\end{array}$ & Semua bagian & 2020 & 2010 \\
\hline $\begin{array}{l}\text { Mengupayakan } \\
0 \% \text { limbah ke } \\
\text { pembuangan } \\
\text { terakhir } \\
\end{array}$ & $\begin{array}{c}\text { Kantor dan } \\
\text { Kantor Distribusi } \\
\text { Regional }\end{array}$ & 2020 & 2010 \\
\hline $\begin{array}{l}\text { Mengurangi } \\
\text { penggunaan air } \\
\text { untuk konsumsi } \\
\text { sebanyak } 25 \%\end{array}$ & Semua Bagian & 2020 & 2010 \\
\hline
\end{tabular}

Tabel 1.1 Komitmen the Body Shop dalam penggunaan energi ramah lingkungan

Berdasarkan tabel tersebut, dapat dilihat bahwa the Body Shop memiliki komitmen kuat untuk mengimplementasikan prinsip fair trade yang kesepuluh, yaitu menghargai lingkungan dan memaksimalkan penggunaan bahan baku yang berkelanjutan.

\section{Kesimpulan}

Isu ekonomi menjadi salah satu isu yang penting bagi perkembangan suatu negara. Setiap negara akan berusaha untuk terus menggerakkan roda perekonomiannya demi menghadapi tantangan globalisasi ekonomi. Seiring dengan perkembangan studi Hubungan Internasional, aktor yang terlibat dalam perekonomian suatu negara tidak lagi hanya pemerintah; melainkan juga aktor non-negara. Perusahaan multinasional merupakan salah satu

\footnotetext{
${ }^{35}$ SWA, The Body Shop Komit Kurangi Emisi CO2 Sebesar 50\% Hingga Tahun 2015, http://swa.co.id/corporate/csr/the-bodyshop-komit-kurangi-emisi-co2-sebesar-50-hingga-tahun-2015 (diakses 10 Mei 2019).
} 
Jurnal Sentris KSMPMI Vol. 2 - 2019

aktor yang aktif dalam mempengaruhi keadaan ekonomi suatu negara; baik secara fisik maupun sosial.

The Body Shop merupakan salah satu perusahaan multinasional yang berdedikasi untuk melancarkan berbagai aksi sosial demi meningkatkan taraf kesejahteraan dari banyak masyarakat di berbagai negara. Dalam upaya untuk memulihkan keadaan finansial di Rwanda pasca tragedi genosida, The Body Shop melaksanakan sebuah program bernama Moringa Community Trade yang didasarkan pada sepuluh prinsip Fair Trade. Pada akhirnya, program ini mampu menggerakkan kembali roda produktivitas negara Rwanda dengan membuat Moringa sebagai salah satu produk The Body Shop yang menerapkan prinsip Fair Trade. Dengan demikian, dapat dilihat bahwa The Body Shop menjadi salah satu contoh nyata perusahaan multinasional yang mampu berpengaruh; atau bahkan berdampak sangat positif; bagi perekonomian suatu negara. Dengan demikian, dapat disimpulkan bahwa The Body Shop sukses mensejahterakan masyarakat Rwanda melalui program Moringa Community Trade yang menerapkan sepuluh prinsip fair trade. 